\title{
Effect of arbuscular mycorrhizal fungus (Glomus caledonium) on the accumulation and metabolism of atrazine in maize (Zea mays L.) and atrazine dissipation in soil
}

\author{
Honglin Huang ${ }^{\text {a }}$, Shuzhen Zhang ${ }^{\mathrm{a}, *}$, Xiao-quan Shan ${ }^{\mathrm{a}}$, Bao-Dong Chen ${ }^{\mathrm{a}}$, \\ Yong-Guan Zhu ${ }^{a}$, J. Nigel B. Bell ${ }^{\mathrm{b}}$ \\ ${ }^{a}$ State Key Laboratory of Environmental Chemistry and Ecotoxicology, Research Center for Eco-Environmental Sciences, \\ Chinese Academy of Sciences, P.O. Box 2871, 18th Shuangqinglu, Haidian District, Beijing 100085, China \\ ${ }^{\mathrm{b}}$ Center for Environmental Policy, Imperial College, London, UK
}

Received 30 August 2005; received in revised form 30 June 2006; accepted 3 July 2006

Arbuscular mycorrhizal fungus increases the accumulation and metabolism of atrazine in maize.

\begin{abstract}
Effects of an arbuscular mycorrhizal (AM) fungus (Glomus caledonium) on accumulation and metabolism of atrazine in maize grown in soil contaminated with different concentrations of atrazine were investigated in a series of pot experiments. Roots of mycorrhizal plants accumulated more atrazine than non-mycorrhizal roots. In contrast, atrazine accumulation in shoot decreased in mycorrhizal compared with nonmycorrhizal plants. No atrazine derivatives were detected in the soil, either with or without mycorrhizal colonization. However, atrazine metabolites, deethylatrazine (DEA) and deisopropylatrazine (DIA), were detected in plant roots and the AM colonization enhanced the metabolism. After plant harvest atrazine concentrations decreased markedly in the soils compared to the initial concentrations. The decreases were the most in rhizosphere soil and then near-rhizosphere soil and the least in bulk soil. Mycorrhizal treatment enhanced atrazine dissipation in the nearrhizosphere and bulk soils irrespective of atrazine application rates.
\end{abstract}

(C) 2006 Elsevier Ltd. All rights reserved.

Keywords: Atrazine; Arbuscular mycorrhizal fungus; Accumulation; Degradation; Maize

\section{Introduction}

Arbuscular mycorrhizal (AM) fungi form a ubiquitous symbiotic relationship with over $90 \%$ of land plants (Smith and Read, 1997), and their effects on crop growth have been widely investigated. AM fungi can significantly extend the volumes of soil to which the host plant root has access, improve plant growth through better nutrition uptake and alleviate toxicity of pollutants (Bolan, 1991; Marschner and Romheld, 1998). The role of AM fungi in plant uptake of heavy metals and

\footnotetext{
* Corresponding author. Tel.: +8610 62849683; fax: +86 1062923563.

E-mail address: szzhang@mail.rcees.ac.cn (S. Zhang).
}

radionuclides has been extensively studied (Leyval et al., 1997; Rufyikiri et al., 2003; Chen et al., 2005). AM fungi are also of benefit to the growth of several plants in soil contaminated with high concentrations of PAHs (Leyval and Binet, 1998). Although the role of AM fungi in soils with organic pollutants is starting to attract the attention in the context of phytoaccumulation and phytoremediation (Joner and Leyval, 2003a), few reports have addressed the effect of AM fungi on the plant uptake and translocation of organic pollutants. Their possible effect on degradation and mineralization of organic pollutants in soil has received far less attention.

The agricultural herbicide atrazine (6-chloro- $N^{\prime}$-ethyl$\mathrm{N}$-isopropyl-1,3,5-triazine-2,4-diamine) is used extensively in many parts of the world to control a variety of weeds, 
primarily in the production of maize (Tomlin, 1994). In the United States alone, nearly 66 million pounds of atrazine are applied each year on three-quarters of the maize fields (EPA, 2003). It is also widely used in other countries, particularly in the developing ones including China. Due to its moderate solubility, atrazine not only occurs frequently in sub-soils, but is also transported downwards (Jayachandran et al., 1994), leading to problems with water supplies (Solomon et al., 1996). Although it is considered as a moderately persistent herbicide with half-lives ranging from several weeks to months, atrazine residues have been reported to remain in agricultural soil for up to 9 years after initial application (Solomon et al., 1996). Hence, pollution of atrazine in soil has been receiving considerable attention.

The fate of atrazine in soils, including uptake by plants and degradation in soils, has been studied extensively ( $\mathrm{Su}$ and $\mathrm{Zhu}$, 2006; Blume et al., 2004; Raveton et al., 1997; Singh et al., 2004). The magnitude and efficiency of organic contaminant transport from soil to plant depend in principle on contaminant level, plant species/composition and exposure time. In addition, plant-microbe symbioses are ubiquitous in most of the natural and arable soils and for a variety of plants, which may mediate plant uptake of the organic contaminants. The degradation and mineralization of atrazine are associated with vegetation. Furthermore, they can be accelerated by bacterial and fungi or by mixed communities in soils (Blume et al., 2004). Research has shown that atrazine can be degraded by ectomycorrhizal (ECM) and ericoid mycorrhizal (ERI) fungi (Donnelly et al., 1993). There is also evidence that ECM fungi can degrade a number of persistent aromatic pollutants (for reviews, see Meharg and Cairney, 2000; Meharg, 2001). AM fungi are the most widespread type of mycorrhiza, which mainly colonize herbaceous plants and provide a direct link between soil and plant roots (Leyval et al., 1997). From this stand of point AM fungi should be crucial for both plant establishment on contaminated sites and influencing the fate of pesticides in soil. But until now we know virtually nothing about the interactions between the pesticides and the AM fungi.

The objective of this work was therefore to assess the AM fungal contribution to the accumulation and the translocation of atrazine in maize and potential degradation. Effect of the AM fungus on atrazine dissipation in soil was also evaluated.

\section{Materials and methods}

\subsection{Host plants}

Seeds of maize (Zea mays L., Nongda 108) were surface sterilized in a $10 \%$ $(\mathrm{v} / \mathrm{v})$ solution of hydrogen peroxide, rinsed with sterile distilled water, and then dipped in a solution of $3 \mathrm{mM}$ calcium nitrate for $4 \mathrm{~h}$. Afterward they were pregerminated on a moist filter paper for $72 \mathrm{~h}$ and were then ready for sowing.

\subsection{Mycorrhizal inoculum}

Inoculum of the AM fungus Glomus caledonium (90036) was propagated for 10 weeks on clover grown in a soil-sand mixture in a greenhouse. The inocula were air-dried and sieved through a 2-mm sieve, which consisted of sandy soil, mycelium, spores and infected root fragments.

\subsection{Pot experiment}

The soil used was collected from an atrazine free area in Anhui Province in China. It was dried and sieved through a 2-mm sieve. Selected physical and chemical properties of the soil are given in Table 1. The growth medium was a 1:4 (v/v) mixture of vermiculite and soil (subsequently referred to as soil), which had a pH of 6.58 (1:2.5 soil to water) and an extractable P content of $3.56 \mathrm{mg} \mathrm{kg}^{-1}$ (Olsen et al., 1954). Basal nutrients at the phosphate level of $30 \mathrm{mg} \mathrm{kg}^{-1}$ soil were added (Pearson and Jakobsen, 1993). The soil was sterilized by $\gamma$-irradiation (10 kGy, $10 \mathrm{MeV} \gamma$ ray) for the elimination of $\mathrm{AM}$ fungi.

The soil was artificially contaminated with atrazine at concentrations of $0.5,2$ and $5 \mathrm{mg} \mathrm{kg}^{-1}$ (dry matter basis). The atrazine solution was prepared by dissolving $22.5 \mathrm{mg}$ of HPLC-Grade atrazine (Sigma) in $150 \mathrm{~mL}$ reagent grade acetone. Aliquots of $10,40,100 \mathrm{~mL}$ of the solution were, respectively, mixed with $10 \%$ of the test soil $(0.3 \mathrm{~kg})$. The contaminated soils were allowed to dry in a fume hood until the acetone volatilized completely, and then mixed well with the rest of the soils $(2.7 \mathrm{~kg})$ by spreading gradually, homogenized and incubated for 1 week.

Each pot contained $650 \mathrm{~g}$ soil samples. Four replicates for each atrazine treatment, $0,0.5,2$ and $5 \mathrm{mg} \mathrm{kg}^{-1}$, were applied to the mycorrhizal and nonmycorrhizal treatments. For mycorrhizal treatments, $60 \mathrm{~g}$ inoculum was mixed with the soil thoroughly and each pot contained about 7000 spores. For the nonmycorrhizal treatments, an equivalent amount of sterilized inoculum together with an aqueous filtrate $(0.25 \mu \mathrm{m}$ pore size $)$ of un-sterilized soil was established to provide a similar microflora except for the absence of the mycorrhizal fungus. Three seeds were transplanted into each pot and two seedlings were left after emergence. All pots were lined with polyethylene bags to avoid crosscontamination and loss of water. The opening of pots was covered with black bag to minimize the growth of algae. The experiment was conducted in a controlled-environment growth chamber that maintained a daily 14-h light period at a light intensity of $250 \mu \mathrm{mol} \mathrm{m}^{-2} \mathrm{~s}^{-1}$ provided by supplementary illumination. The temperature was $25^{\circ} \mathrm{C}$ for daytime and $20^{\circ} \mathrm{C}$ for nighttime. The relative humidity was kept at $70 \%$. Plants grew for 4 weeks. Deionized water was added as required to maintain moisture content at $60-70 \%$ of field water holding capacity. A solution of $\mathrm{NH}_{4} \mathrm{NO}_{3}$ was added on 14, 21 and 24 days after sowing to provide a total of $120 \mathrm{mg} \mathrm{N}$ pot $^{-1}$.

\subsection{Sample preparation and analysis}

Prior to harvest pots were left without watering for 1 day. Shoots and roots were harvested separately. Bulk soil was collected by gently crushing the soil and shaking the roots ( $70-80 \%$ of the soil mass). Soil that required continued, vigorous rubbing and shaking of the root system was classified as near-rhizosphere soil (6-10\% of soil mass). Afterward rhizosphere soil $(0.8-3 \%$ of soil mass) was obtained by shaking the soil adhering tightly onto the intact root system. The roots were then washed with $100 \mathrm{~mL}$ of deionized water and the soil particles were recovered on a fiber paper and combined to the rhizosphere soil. Shoot and root samples were rinsed with distilled water, wiped with tissue paper, immediately weighed, and then stored at $4{ }^{\circ} \mathrm{C}$.

To estimate the root colonization of AM fungus, a subsample of $1 \mathrm{~g}$ fresh root was randomly taken and cut into $0.5-1 \mathrm{~cm}$ pieces. Roots were cleared in $10 \% \mathrm{KOH}$ for $10 \mathrm{~min}$ at $90^{\circ} \mathrm{C}$ in a water bath, rinsed in water, and then

Table 1

Selected physical and chemical properties of the soil

\begin{tabular}{lc}
\hline Soil type & Alfisols \\
\hline $\mathrm{pH}\left(\mathrm{H}_{2} \mathrm{O}\right)$ & 6.9 \\
$\mathrm{NaHCO}_{3}$-extractable P $\left(\mathrm{mg} \mathrm{P} \mathrm{kg}^{-1}\right)$ & 4.5 \\
$\mathrm{CEC}\left(\mathrm{cmol} \mathrm{kg}^{-1}\right)$ & 25.0 \\
$\mathrm{OM}(\%)$ & 2.09 \\
$\mathrm{DOC}\left(\mathrm{mg} \mathrm{kg}^{-1}\right)$ & 658 \\
$\mathrm{Clay}(\% \mathrm{v} / \mathrm{v})$ & 32.2 \\
Silt $(\% \mathrm{v} / \mathrm{v})$ & 59.1 \\
Sand $(\% \mathrm{v} / \mathrm{v})$ & 8.7 \\
\hline
\end{tabular}


stained with $0.1 \%$ trypan blue for $3-5 \mathrm{~min}$ at $90{ }^{\circ} \mathrm{C}$ in a water bath. The mycorrhizal colonization level was evaluated by the grid line intersect method (Phillips and Hayman, 1970). Briefly, subsamples of these stained roots were arranged lengthwise on a thin layer of PVA mounted on a microscope slide. Use a hairline graticule inserted into the eyepiece of a compound microscope to act as a line of intersection with the roots. AM fungal structures at each intersection were calculated at $\times 200$ magnification.

Stored plant samples were cut and homogenized using a mortar and pestle. Three grams of the subsamples were extracted twice with $80 \mathrm{~mL}$ of $80 \%$ aqueous methanol by shaking the suspension on a rotary for $48 \mathrm{~h}$. The extracts were filtrated and combined, and then extracted successively with $50 \mathrm{~mL}$ of petroleum ether/dichloromethane $(65: 35, \mathrm{v} / \mathrm{v})$ for three times. Supernatants were passed through anhydrous $\mathrm{Na}_{2} \mathrm{SO}_{4}$ columns and collected. The eluates were concentrated into a small volume $(1-2 \mathrm{~mL})$ by rotary evaporation, dissolved with $30 \mathrm{~mL}$ petroleum ether, and re-extracted three times with $20 \mathrm{~mL}$ of acetonitrile. The acetonitrile fractions were combined, concentrated and evaporated off. The residues were dissolved with petroleum ether and cleaned with Florisil columns. The concentrations of atrazine in extracts were analyzed with an Agilent 6890 gas chromatograph equipped with a detector of NPD using a HP-5 capillary column $(0.32 \mathrm{~mm} \times 30 \mathrm{~m}, 0.25 \mu \mathrm{m}$ film thickness $)$. The column oven was programmed from an initial temperature of $70^{\circ} \mathrm{C}$ for $2 \mathrm{~min}$ to $220^{\circ} \mathrm{C}$ at a rate of $20^{\circ} \mathrm{C} \mathrm{min}^{-1}$, held for $1 \mathrm{~min}$, and then ramped at a rate of $4{ }^{\circ} \mathrm{C} \mathrm{min}{ }^{-1}$ to $240{ }^{\circ} \mathrm{C}$ with a final hold time of $10 \mathrm{~min}$. The detector and the injector were maintained at $300^{\circ} \mathrm{C}$ and $250{ }^{\circ} \mathrm{C}$, respectively; the injector was in the splitless mode. The extraction and analysis procedure were also performed on $5 \mathrm{~g}$ of soil samples for the bulk and near-rhizosphere soils and on the whole rhizosphere soil. Atrazine in the washing water used for obtaining the whole rhizosphere soil was also extracted and analyzed, which was only $1-4 \%$ of atrazine contents in rhizosphere soils and therefore not included. To determine analytical recovery, pesticides were spiked into the soil and the ground plant materials. Recoveries ranged from 85 to $90 \%(\mathrm{RSD}=6.8 \%, n=5)$.

\subsection{Data analysis}

The data were subjected to an analysis of variance (ANOVA) using the Origin 7.0 with different levels of atrazine treatment, AM treatment, and atrazine-treatment/AM-treatment interactions as sources of variation.

\section{Results}

\subsection{Root colonization and plant biomass}

No mycorrhizal colonization was observed in noninoculated control plants. Increasing atrazine concentration in the soil decreased the mycorrhizal root colonization concentrations between 0 and $2 \mathrm{mg} \mathrm{kg}^{-1}$ for the inoculate treatment. However, the colonization increased slightly when atrazine concentration in soil was $5 \mathrm{mg} \mathrm{kg}^{-1}$. Atrazine concentration did not significantly $(p>0.05)$ affect the dry weights of maize shoots and roots in any of the treatments (Table 2).

\subsection{Accumulation of atrazine in maize with and without mycorrhizal colonization}

The accumulation of atrazine in maize is shown in Fig. 1. Atrazine in both roots and shoots of maize grown in unspiked control soil was not detected. Roots accumulated much more atrazine than shoots. With the increase in atrazine concentration in soils, the accumulation of atrazine in roots was significantly elevated irrespective of the inoculation treatments. Mycorrhizal inoculated root consistently accumulated more atrazine than non-mycorrhizal root. In contrast to the roots, inoculation caused a decrease in atrazine concentrations in the shoots. The atrazine concentration was increased in the inoculated root by $132.4-260.5 \%$ compared to the non-inoculated root. However, atrazine accumulation in inoculated shoots decreased by $57.2,31.3,55.5 \%$ when the soil atrazine concentration was $0.5,2,5 \mathrm{mg} \mathrm{kg}^{-1}$, respectively. Another interesting phenomenon (Fig. 1) was that atrazine concentration in shoots of mycorrhizal maize was not consistently increased with the increasing atrazine application in soil; the shoots accumulated less atrazine at $5 \mathrm{mg} \mathrm{kg}^{-1}$ soil application rate than at the rate of $2 \mathrm{mg} \mathrm{kg}^{-1}$.

\subsection{Metabolism of atrazine in maize roots}

Deethylatrazine (DEA) (2-amino-4-chloro-6-isopropylanine-striazine) and deisopropylatrazine (DIA) (2-amino-4-chloro6-ethylamino-s-triazine) were the most important atrazine metabolites and therefore were analyzed in plant and soil samples. None of them were detected in soils either with or without AM. However, DEA and DIA were detected in maize roots in all the treatments and AM inoculation significantly enhanced the concentration (Table 3). For instance, with the application of atrazine at $5 \mathrm{mg} \mathrm{kg}^{-1}$ the metabolite concentrations of DEA and DIA in mycorrhizal colonized roots were 2.6 and 3.8 times, respectively, as high as in the non-inoculated roots.

\subsection{Dissipation of atrazine in soils}

Fig. 2 shows the residual concentrations of atrazine in the rhizosphere, near-rhizosphere and bulk soils. After plant harvest atrazine concentrations decreased markedly in the soils compared to the initial concentrations. The decreases were the most in rhizosphere soils and then near-rhizosphere soils

Table 2

Mycorrhizal colonization and its effect on the growth of plant mean $\pm \mathrm{SE}$

\begin{tabular}{|c|c|c|c|c|c|c|}
\hline \multirow{3}{*}{$\begin{array}{l}\text { Concentration of atrazine added } \\
\text { in the soil }\left(\mathrm{m} \mathrm{kg}^{-1}\right)\end{array}$} & \multirow{2}{*}{\multicolumn{2}{|c|}{ Root colonization (\% of root length) }} & \multicolumn{4}{|c|}{ Biomass $\left(\mathrm{g} \mathrm{pot}^{-1}\right)$} \\
\hline & & & \multicolumn{2}{|l|}{ Shoot } & \multicolumn{2}{|l|}{ Root } \\
\hline & Non-inoculated & Inoculated & Non-inoculated & Inoculated & Non-inoculated & Inoculated \\
\hline 0.5 & 0 & $53.9 \pm 1.1$ & $4.67 \pm 0.09$ & $4.28 \pm 0.08$ & $7.33 \pm 0.22$ & $7.47 \pm 0.22$ \\
\hline 2.0 & 0 & $46.1 \pm 0.9$ & $5.00 \pm 0.08$ & $4.50 \pm 0.09$ & $6.40 \pm 0.19$ & $6.13 \pm 0.18$ \\
\hline 5.0 & 0 & $63.9 \pm 1.2$ & $4.83 \pm 0.09$ & $4.40 \pm 0.08$ & $6.20 \pm 0.19$ & $6.17 \pm 0.19$ \\
\hline
\end{tabular}



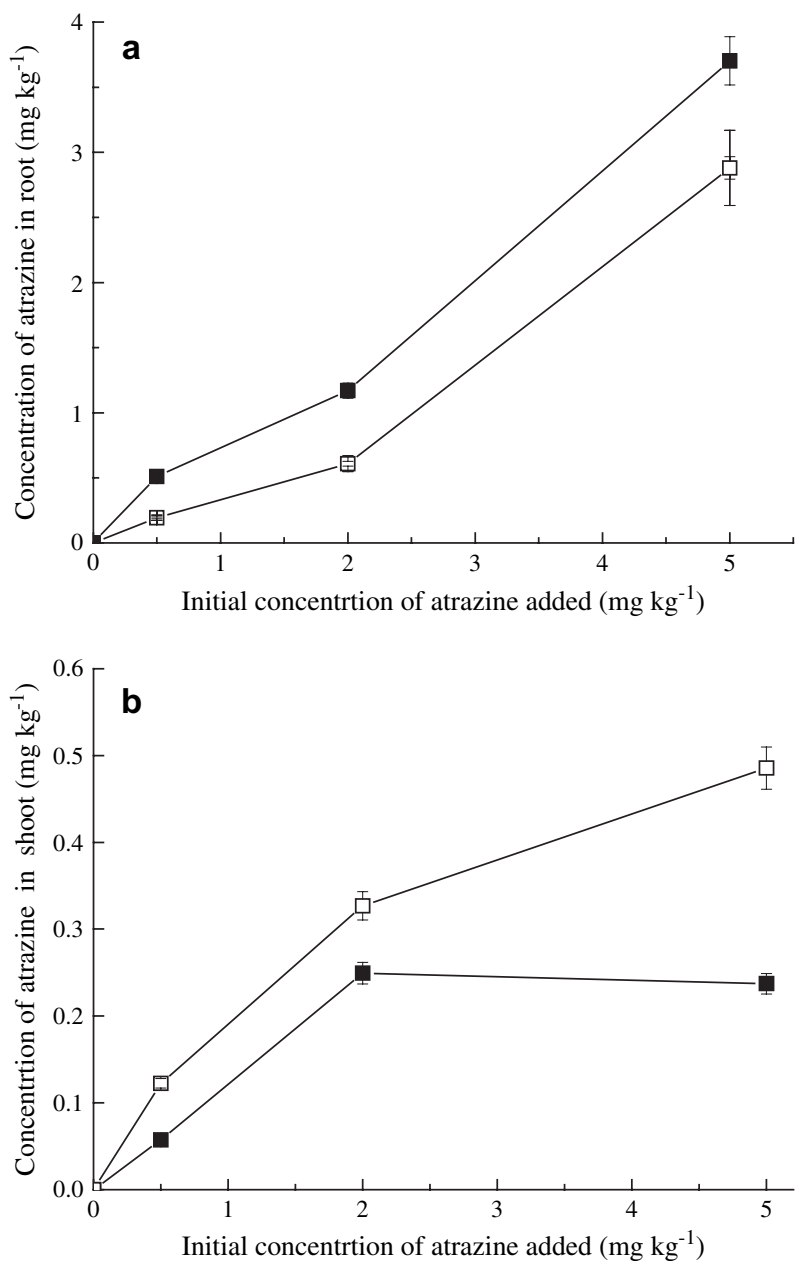

Fig. 1. Atrazine concentration in maize root (a) and shoot (b) after cultivation in the presence ( $\square$ ) or absence ( $\square$ ) of AM fungi for 4 weeks. These concentrations are on the fresh weight basis and represented as mean \pm standard deviation; $n=4$.

and the least in bulk soils. Mycorrhizal treatment enhanced atrazine dissipation in the near-rhizosphere and bulk soils irrespective of atrazine application rates. For instance, when the initial application atrazine concentration was $2.0 \mathrm{mg} \mathrm{kg}^{-1}$, a reduction of $73.7 \%$ in atrazine concentration in the bulk soil was observed in the mycorrhizal treatment, whereas the reduction was $31.4 \%$ in the non-inoculated treatment. No significant differences in dissipation of atrazine in rhizosphere soil were observed between mycorrhizal and non-mycorrhizal treatments.

\section{Discussion}

Atrazine is a highly toxic compound to plants, but the application rate in this study did not show a detrimental effect on maize growth. The dry weights of shoot and root irrespective of the inoculation treatments were not significantly different. The detoxification of herbicides in plant has been attributed to the conjugation with glutathione catalysed by Glutathion-s-Transferases (Hatton et al., 1996). Increasing atrazine application rates in soil from 0 to $2 \mathrm{mg} \mathrm{kg}^{-1}$ decreased mycorrhizal root colonization concentrations, but the colonization increased slightly when the atrazine concentration in soil was $5 \mathrm{mg} \mathrm{kg}^{-1}$. Interactions between organic pollutants and AM fungi have seldom been investigated and no explicit mechanisms have been proposed. The increased mycorrhizal colonization at high atrazine concentration could be caused by tissue dilution of the pollutants due possibly to improved $\mathrm{P}$ nutrition or the development of tolerance to the pollutant by the fungus. In this experiment, tissue dilution is unlikely because mycorrhizal colonization had little effect on plant yield. Phosphate $\left(30 \mathrm{mg} \mathrm{kg}^{-1}\right)$ was added to the culture mixture at the start of the experiment, thus it is unlikely to have P deficiency. Therefore, development of tolerance by the AM fungi could be the possible reason for the increased colonization with high atrazine application.

Compared with the non-inoculation treatment, AM fungi significantly increased atrazine concentration in roots, but greatly decreased atrazine concentration in shoots. AM fungi enhanced atrazine uptake in maize root but inhibited its transportation from root to shoot. This phenomenon could be attributed to the increased atrazine adsorption on roots by mycorrhizal colonization. Nedumpara et al. (1999) confirmed that atrazine adsorption on excised roots segments was increased by AM fungus for soybean and maize. In addition AM fungi may influence the uptake of atrazine via the mycorrhizosphere effect, whereby their mycelial systems in soil may influence the structure and activities of soil microbial assemblages (see Smith and Read, 1997).

There is evidence that ECM fungi can degrade a wide range of persistent aromatic pollutants (for reviews, see Meharg and Cairney, 2000; Meharg, 2001). The degradation effect of AM fungi in soil or plant has not been addressed. The only report available was by Donnelly et al. (1993) in which he observed increased atrazine degradation by mycorrhizal fungi in an in vitro culture experiment. The present study demonstrates that atrazine can be degraded to DEA and DIA in the maize roots and the AM fungi enhance the degradation significantly

Table 3

Concentrations of DIA and DEA in maize roots with and without AM inoculation

\begin{tabular}{|c|c|c|c|c|}
\hline \multirow{2}{*}{$\begin{array}{l}\text { Concentration of atrazine } \\
\text { added }\left(\mathrm{mg} \mathrm{kg}^{-1}\right)\end{array}$} & \multicolumn{2}{|c|}{ Concentration of DIA $\left(\mathrm{mg} \mathrm{kg}^{-1}\right)$} & \multicolumn{2}{|c|}{ Concentration of DEA $\left(\mathrm{mg} \mathrm{kg}^{-1}\right)$} \\
\hline & Non-inoculated & Inoculated & Non-inoculated & Inoculated \\
\hline 0 & 0 & 0 & 0 & 0 \\
\hline 0.5 & 0.05 & 0.11 & 0.04 & 0.08 \\
\hline 2.0 & 0.12 & 0.16 & 0.16 & 0.27 \\
\hline 5.0 & 0.40 & 1.41 & 0.29 & 0.74 \\
\hline
\end{tabular}



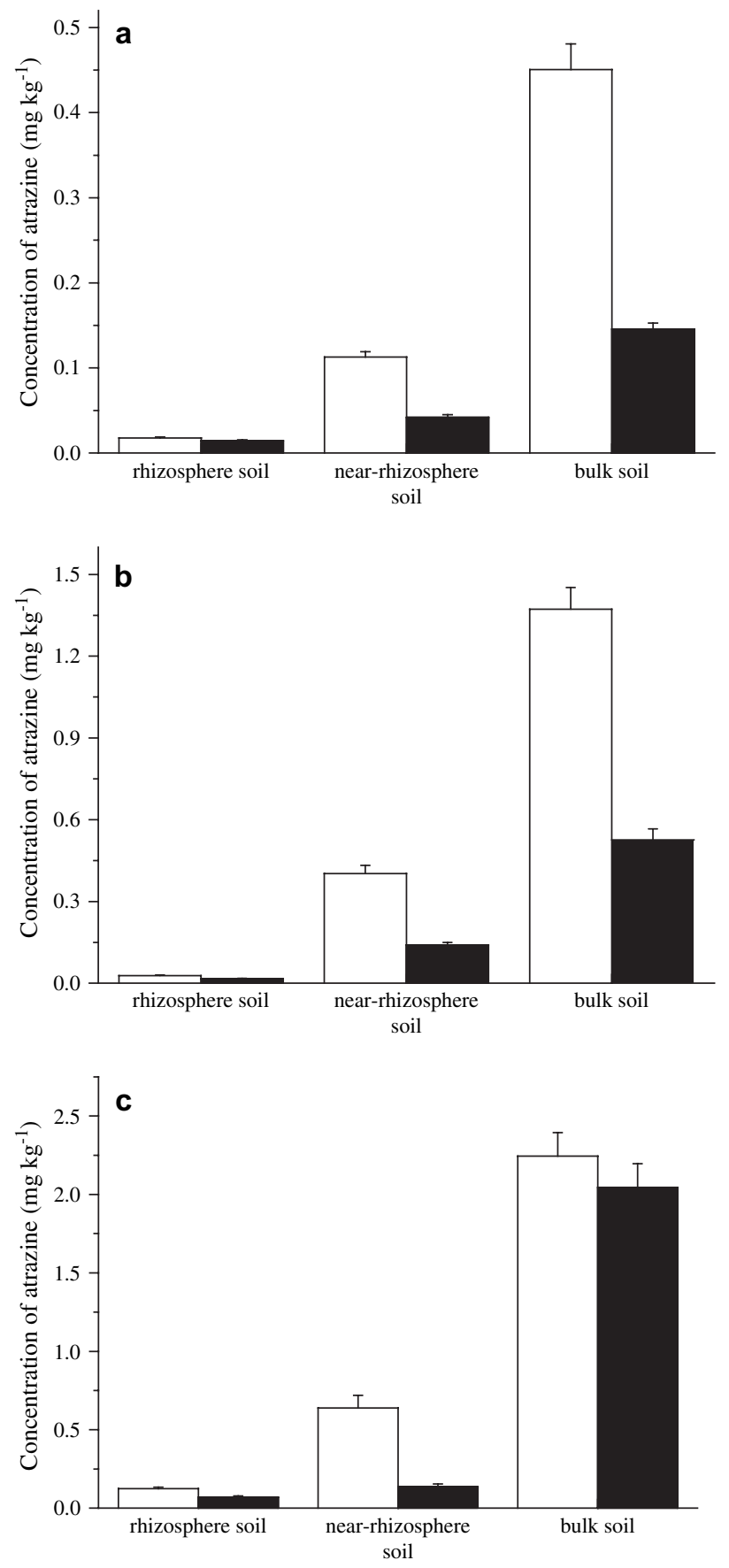

Fig. 2. The residual concentration of atrazine in the rhizosphere, near-rhizosphere and bulk soils for (a) $0.5 \mathrm{mg} \mathrm{kg}^{-1}$, (b) $2 \mathrm{mg} \mathrm{kg}^{-1}$ and (c) $5 \mathrm{mg} \mathrm{kg}^{-1}$ of atrazine applied after cultivating maize in the presence ( $\boldsymbol{\square})$ or absence ( $\square$ ) of AM fungi for 4 weeks. Values are mean \pm standard deviation; $n=4$.

$(p<0.01)$. No atrazine metabolites were detected even in the rhizosphere soils either with or without mycorrhizal treatment. The fact that only the metabolites DEA and DIA were detected in the plant roots could contribute to the important role of the plant-derived enzymes in roots in degradation and then the metabolites assimilated into the plant tissue (Boyajian and Carriera, 1997). AM fungi were reported to obligate symbionts with little or no capacity for degradation of organics (Joner and Leyval, 2003b). Therefore, the increasing enzyme activity and microorganism stimulated by colonization was the possible reason for the enhanced metabolism in mycorrhizal colonized roots.

The residual concentrations of atrazine in soils decreased significantly (Fig. 2) after cropping, especially in the rhizosphere soil. Mycorrhizal treatment enhanced the dissipation of atrazine in near-rhizosphere and bulk soils. Taking the initial application concentration of $2.0 \mathrm{mg} \mathrm{kg}^{-1}$ atrazine as an example, a reduction of $73.7 \%$ in atrazine concentration in bulk soil was observed in the mycorrhizal treatment, whereas the reduction was $31.4 \%$ in the non-inoculated treatment. The presence of AM led to an additional $42.3 \%$ reduction in atrazine concentration. The mechanisms behind enhanced dissipation of atrazine with the presence of AM fungus are not clear and may be apprehended as changed root surface properties, increased microbial activity in soil and formation of new interface of soil-plant interactions. Mycorrhizal treatment even increased the dissipation of atrazine in bulk soil, which contributed to the action of mycorrhizal hyphae on the roots and extending the rhizosphere into the bulk soil by creating a new interface of soil-plant interactions.

\section{Conclusion}

The AM fungus can enhance the accumulation of atrazine in maize roots but decrease the transport of atrazine from root to shoot. Degradation of atrazine in roots was observed and the AM fungus contributes to higher degradation of atrazine in roots. The residual concentrations of atrazine in soils decreased significantly after cropping and mycorrhizal treatment enhanced atrazine dissipation in the soil. This study confirmed the beneficial effects of AM fungi on atrazine accumulation in plant and the potential role of AM fungi in phytoremediation of atrazine contaminated soils.

\section{Acknowledgements}

This work was funded by National Basic Research Program (2003CB415004) and the National Natural Science Foundation of China (206770XX).

\section{References}

Blume, E., Bischoff, M., Moorman, T.B., Turco, R.F., 2004. Degradation and binding of atrazine in surface and subsurface soils. Journal of Agricultural and Food Chemistry 52, 7382-7388.

Bolan, N.S., 1991. A critical review on the role of mycorrhizal fungi in the uptake of phosphorus by plants. Plant and Soil 134, 189-207.

Boyajian, G., Carriera, L.H., 1997. Phytoremediation: a clean transition from laboratory to marketplace. Nature Biotechnology 15, 127-128.

Chen, B.D., Roos, P., Borggaard, O.K., Zhu, Y.G., Jakobsen, I., 2005. Mycorrhiza and root hairs in barley enhance acquisition of phosphorus and uranium from phosphate rock but mycorrhiza decreases root to shoot uranium transfer. New Phytologist 165, 591-598.

Donnelly, P.K., Entry, J.A., Crawford, D.L., 1993. Degradation of atrazine and 2,4-dichlorophenoxyacetic acid by mycorrhizal fungi at three nitrogen concentrations in vitro. Applied and Environmental Microbiology 59, 2642-2647. 
EPA, 2003. Interim registration eligibility decision for atrazine. Case number 0062. Office of Prevention, Pesticide and Toxic Substances, US Environmental Protection Agency. $<$ http://www.epa.gov/oppsrrd1/REDs/atrazine_ired.pdf $>$.

Hatton, P.J., Cole, D.J., Edwards, R., 1996. Influence of plant age on glutathione levels and glutathione transferases involved in herbicide detoxification in corn (Zea mays L.) and giant foxtail (Setaria faberi Herm). Pesticide Biochemistry and Physiology 54, 199-209.

Jayachandran, K., Steinheimer, T.R., Somasundaram, L., Moorman, T.B., Kanwar, R.S., Coats, J.R., 1994. Occurrence of atrazine and degradates as contaminants of subsurface drainage and shallow groundwater. Journal of Environmental Quality 23, 311-319.

Joner, E.J., Leyval, C., 2003a. Phytoremediation of organic pollutants using mycorrhizal plant: a new aspect of rhizosphere interactions. Agronomie 23, 495-502.

Joner, E.J., Leyval, C., 2003b. Rhizosphere gradients of polycyclic aromatic hydrocarbon (PAH) dissipation in two industrial soils and the impact of arbuscular mycorrhiza. Environmental Science and Technology 37, $227-234$.

Leyval, C., Binet, P., 1998. Effect of polyaromatic hydrocarbons (PAHs) in soil on arbuscular mycorrhizal plants. Journal of Environmental Quality 27, 402-407.

Leyval, C., Turnau, K., Haselwandter, K., 1997. Effect of heavy metal pollution on mycorrhizal colonization and function: physiological, ecological and applied aspects. Mycorrhiza 7, 139-153.

Marschner, H., Romheld, D.J., 1998. Role of root growth, arbuscular mycorrhiza and root exudates for the efficiency in nutrient acquisition. Field Crops Research 56, 203-207.

Meharg, A.A., 2001. The potential for utilizing mycorrhizal associations in soil bioremediation. In: Gadd, G.M. (Ed.), Fungi in Bioremediation. Cambridge University Press, Cambridge, U.K., pp. 445-455.

Meharg, A.A., Cairney, J.W.C., 2000. Ectomycorrhizas: extending the capabilities or rhizosphere remediation? Soil Biology and Biochemistry 32, $1475-1484$.
Nedumpara, M.J., Moorman, T.B., Jayachandran, K., 1999. Effect of a vesicular-arbuscular mycorrhizal fungus (Glomus epigaeus) on herbicide uptake by roots. Biology and Fertility of Soils 30, 75-82.

Olsen, S.R., Cole, C.V., Watanabe, F.S., Dean, L.A., 1954. Estimation of available phosphorus in soils by extraction with sodium bicarbonate. USDA Circular No. 939

Pearson, J.N., Jakobsen, I., 1993. The relative contribution of hyphae and roots to phosphorus uptake by arbuscular mycorrhizal plants measured by dual labeling with ${ }^{32} \mathrm{P}$ and ${ }^{33} \mathrm{P}$. New Phytologist 124, 489-494.

Phillips, J.M., Hayman, D.S., 1970. Improved procedures for clearing and staining parasitic and vesicular-arbuscular mycorrhizal fungi for rapid assessment of infection. Transactions of the British Mycological Society $55,158-161$.

Raveton, M., Ravnel, P., Serre, A.M., Nurit, F., Tissut, M., 1997. Kinetics of uptake and metabolism of atrazine in model plant systems. Pesticide Science 49, 157-163.

Rufyikiri, G., Thiry, Y., Declerck, S., 2003. Contribution of hyphae and roots to uranium uptake and translocation by arbuscular mycorrhizal carrot roots under root-organ culture conditions. New Phytologist 158, 391-399.

Singh, N., Megharaj, M., Kookana, R.S., Naidu, R., Sethunathan, N., 2004. Atrazine and simazine degradation in Pennisetum rhizosphere. Chemosphere $56,257-263$

Smith, S.E., Read, D.J., 1997. Mycorrhizal Symbiosis, second ed. Academic Press, London.

Solomon, K.R., Baker, D.B., Richards, P., Dixon, K.R., Klaine, S.J., La Point, T.W., et al., 1996. Ecological risk assessment of atrazine in North American surface waters. Society of Environmental Toxicology and Chemistry: Annual Review Issue 15, 31-76.

Su, Y.H., Zhu, Y.-G., 2006. Bioconcentration of atrazine and chlorophenols into roots and shoots of rice seedlings. Environmental Pollution 139, $32-39$.

Tomlin, C., 1994. The Pesticide Manual, tenth ed. British Crop Protection Council, Farnham, United Kingdom. 